\title{
LOSS OF RECENT MEMORY AFTER BILATERAL HIPPOCAMPAL LESIONS
}

\author{
BY \\ WILLIAM BEECHER SCOVILLE and BRENDA MILNER
}

\begin{abstract}
From the Department of Neurosurgery, Hartford Hospital, and the Department of Neurology and Neurosurgery, McGill University, and the Montreal Neurological Institute, Canada
\end{abstract}

In 1954 Scoville described a grave loss of recent memory which he had observed as a sequel to bilateral medial temporal-lobe resection in one psychotic patient and one patient with intractable seizures. In both cases the operations had been radical ones, undertaken only when more conservative forms of treatment had failed. The removals extended posteriorly along the mesial surface of the temporal lobes for a distance of approximately $8 \mathrm{~cm}$. from the temporal tips and probably destroyed the anterior two-thirds of the hippocampus and hippocampal gyrus bilaterally, as well as the uncus and amygdala. The unexpected and persistent memory deficit which resulted seemed to us to merit further investigation. We have therefore carried out formal memory and intelligence testing of these two patients and also of eight other patients who had undergone similar, but less radical, bilateral medial temporallobe resections.* The present paper gives the results of these studies which point to the importance of the hippocampal complex for normal memory function. Whenever the hippocampus and hippocampal gyrus were damaged bilaterally in these operations some memory deficit was found, but not otherwise. We have chosen to report these findings in full, partly for their theoretical significance, and partly as a warning to others of the risk to memory involved in bilateral surgical lesions of the hippocampal region.

\section{Operations}

During the past seven years in an effort to preserve the overall personality in psychosurgery some 300 fractional lobotomies have been performed, largely on seriously ill schizophrenic patients who had failed to respond to other forms of treatment. The aim in these fractional procedures was to secure as far as possible any beneficial effects a complete frontal lobotomy might have, while at the same time avoiding its undesirable side-effects. And it was in fact

* These further psychological examinations by one of the authors, B. M., were made possible through the interest of Dr. Wilder Penfield. found that undercutting limited to the orbital surfaces of both frontal lobes has an appreciable therapeutic effect in psychosis and yet does not cause any new personality deficit to appear (Scoville, Wilk, and Pepe, 1951). In view of the known close relationship between the posterior orbital and mesial temporal cortices (MacLean, 1952; Pribram and Kruger, 1954), it was hoped that still greater psychiatric benefit might be obtained by extending the orbital undercutting so as to destroy parts of the mesial temporal cortex bilaterally. Accordingly, in 30 severely deteriorated cases, such partial temporallobe resections were carried out, either with or without orbital undercutting. The surgical procedure has been described elsewhere (Scoville, Dunsmore, Liberson, Henry, and Pepe, 1953) and is illustrated anatomically in Figs. 1 to 4 . All the removals have been bilateral, extending for varying distances along the mesial surface of the temporal lobes. Five were limited to the uncus and underlying amygdaloid nucleus; all others encroached also upon the anterior hippocampus, the excisions being carried back $5 \mathrm{~cm}$. or more after bisecting the tips of the temporal lobes, with the temporal horn constituting the lateral edge of resection. In one case only in this psychotic group all tissue mesial to the temporal horns for a distance of at least $8 \mathrm{~cm}$. posterior to the temporal tips was destroyed, a removal which presumably included the anterior two-thirds of the hippocampal complex bilaterally.

An equally radical bilateral medial temporal-lobe resection was carried out in one young man (H. M.) with a long history of major and minor seizures uncontrollable by maximum medication of various forms, and showing diffuse electro-encephalographic abnormality. This frankly experimental operation was considered justifiable because the patient was totally incapacitated by his seizures and these had proven refractory to a medical approach. It was suggested because of the known epileptogenic qualities of the uncus and hippocampal complex and because of the relative absence of post-operative 


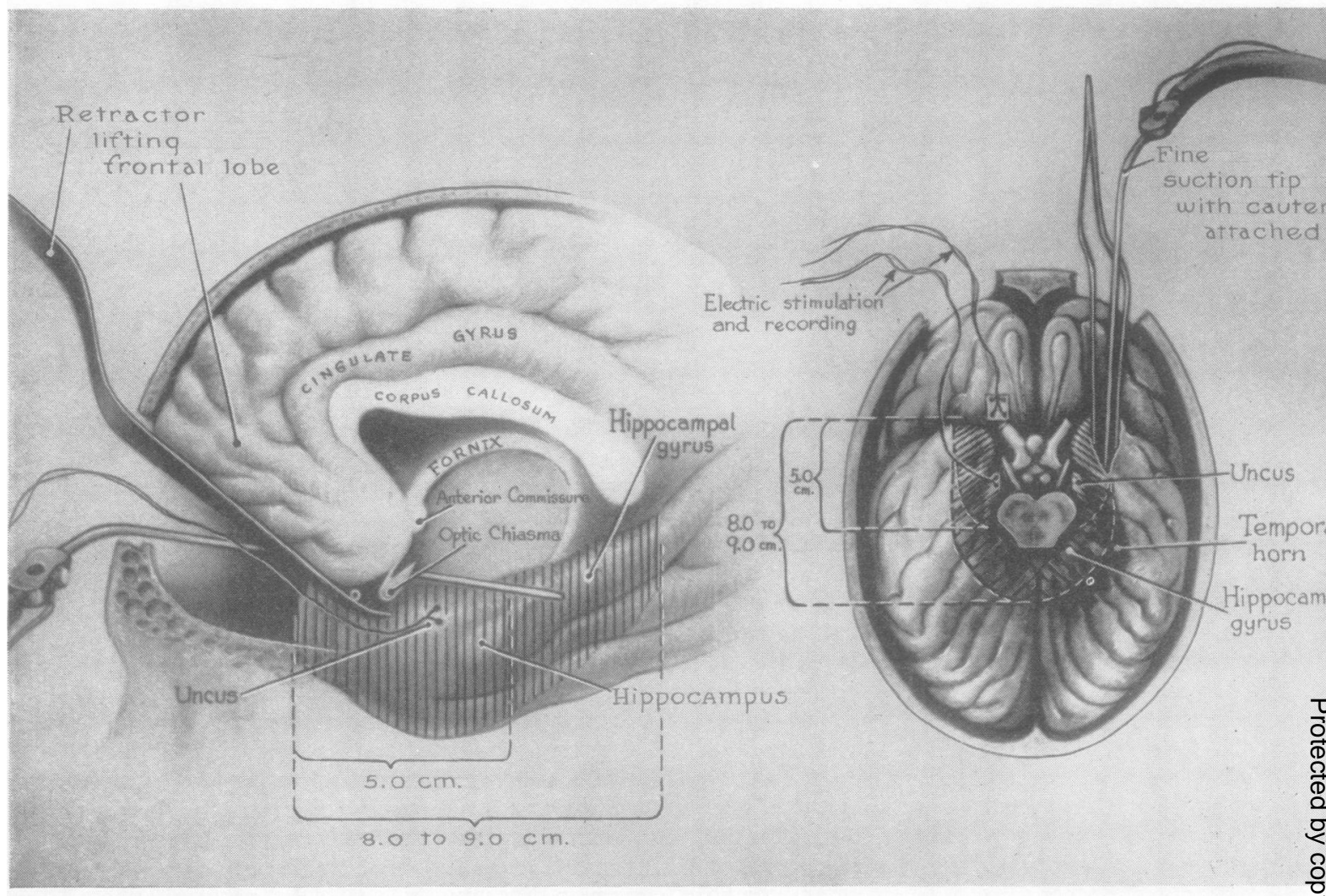

Fig. 1.-Area removed bilaterally from the medial temporal lobes.demonstrating $5 \mathrm{~cm}$. as well as $8 \mathrm{~cm}$. removals through supra-orbital trephines.

seizures in our temporal-lobe resections as compared with fractional lobotomies in other areas. The operation was carried out with the understanding and approval of the patient and his family, in the hope of lessening his seizures to some extent. At operation the medial surfaces of both temporal lobes were exposed and recordings were taken from both surface and depth electrodes before any tissue was removed; but again no discrete epileptogenic focus was found. Bilateral resection was then carried out, extending posteriorly for a distance of $8 \mathrm{~cm}$. from the temporal tips.

\section{Results}

The psychiatric findings bearing upon the treatment of schizophrenia have already been reported (Scoville and others, 1953). Briefly, it was found that bilateral resections limited to the medial portions of the temporal lobes were without significant therapeutic effect in psychosis, although individual patients (including the one with the most radical removal) did in fact show some improvement. There have been no gross changes in personality. This is particularly clear in the case of the epileptic, nonpsychotic patient whose present cheerful placidity does not differ appreciably from his pre-operative status and who, in the opinion of his family, has shown no personality change. Neurological changes in the group have also been minimal. The incidence and severity of seizures in the epileptic patient were sharply reduced for the first year after operation, and although he is once again having both major and minor attacks, these attacks no longer leave him stuporous, as they formerly did. It has therefore been possible to reduce his medication considerably. As far as general intelligence is concerned, the epileptic patient has actually improved slightly since operation, possibly because he is less drowsy than before. The psychotic patients were for the most part too disturbed before operation for finer testing of higher mental functions to be carried out, but certainly there is no indication of any general intellectual impairment resulting from the operation in those patients for whom the appropriate test data are available.

There has been one striking and totally unexpected 


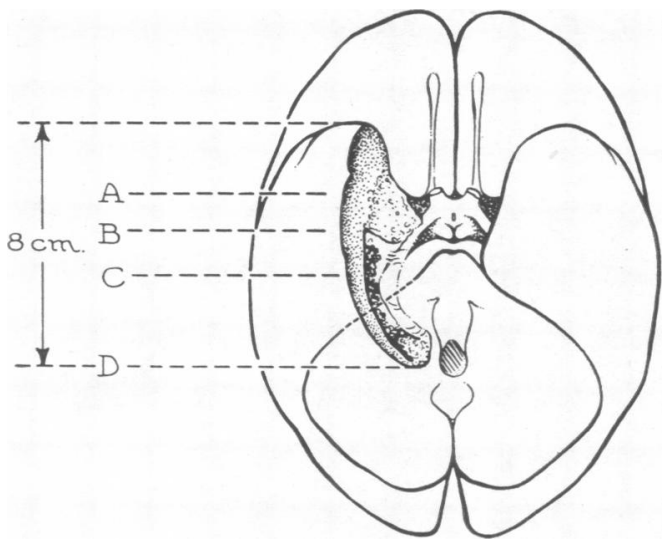

Fig. 2.-Diagrammatic cross-sections of human brain illustrating extent of attempted bilateral medial temporal lobe resection in the radical operation. (For diagrammatic purposes the resection has been shown on one side only.)

$A$
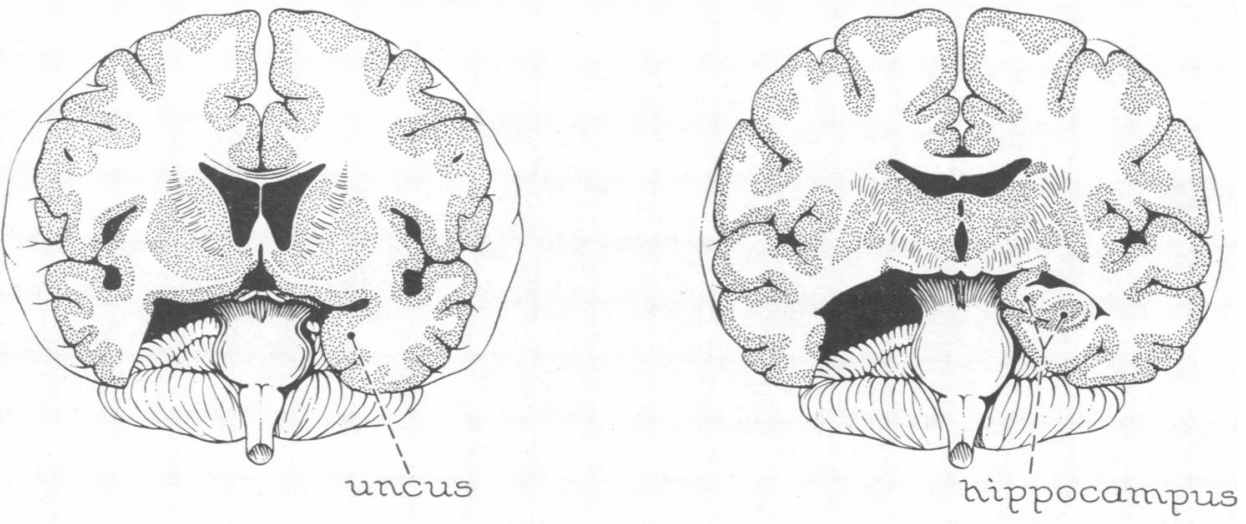

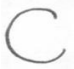
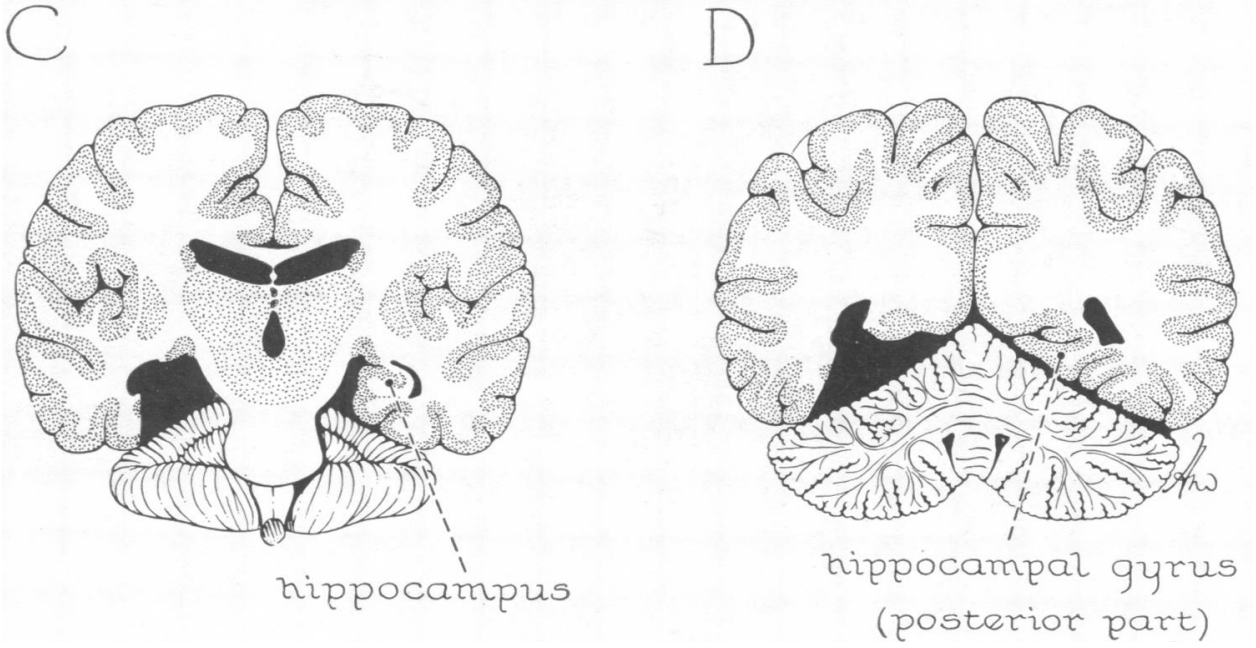


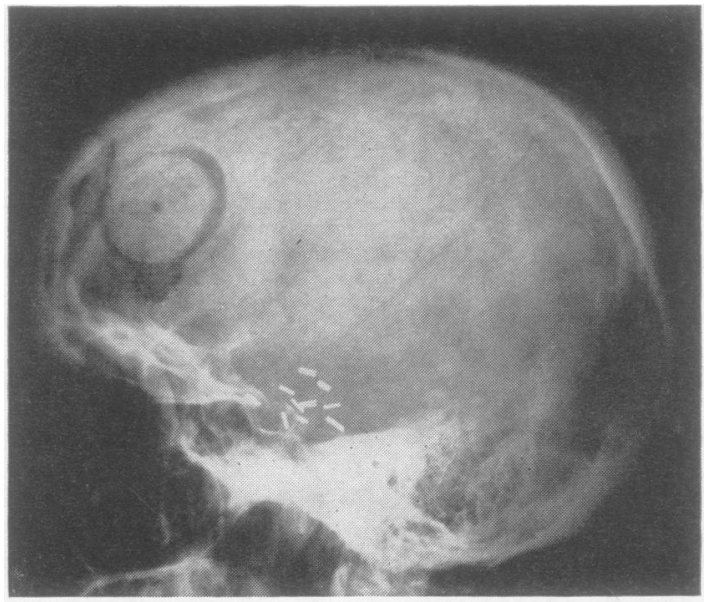

Fig. 3.-Post-operative skull radiograph with silver clip markers outlining extent of bilateral resections limited to the uncus and amygdala.

behavioural result: a grave loss of recent memory in those cases in which the medial temporal-lobe resection was so extensive as to involve the major portion of the hippocampal complex bilaterally. The psychotic patient having the most radical excision (extending $8 \mathrm{~cm}$. from the tips of the temporal lobes bilaterally) has shown a profound post-operative memory disturbance, but unfortunately this was not recognized at the time because of her disturbed emotional state. In the non-psychotic patient the loss was immediately apparent. After operation this young man could no longer recognize the hospital staff nor find his way to the bathroom, and he seemed to recall nothing of the day-to-day events of his hospital life. There was also a partial retrograde amnesia, inasmuch as he did not remember the death of a favourite uncle three years previously, nor anything of the period in hospital, yet could recall some trivial events that had occurred just before his admission to the hospital. His early memories were apparently vivid and intact.

This patient's memory defect has persisted without improvement to the present time, and numerous illustrations of its severity could be given. Ten months ago the family moved from their old house to a new one a few blocks away on the same street; he still has not learned the new address, though remembering the old one perfectly, nor can he be trusted to find his way home alone. Moreover, he does not know where objects in continual use are kept; for example, his mother still has to tell him where to find the lawn mower, even though he may have been using it only the day before. She also states that he will do the same jigsaw puzzles day

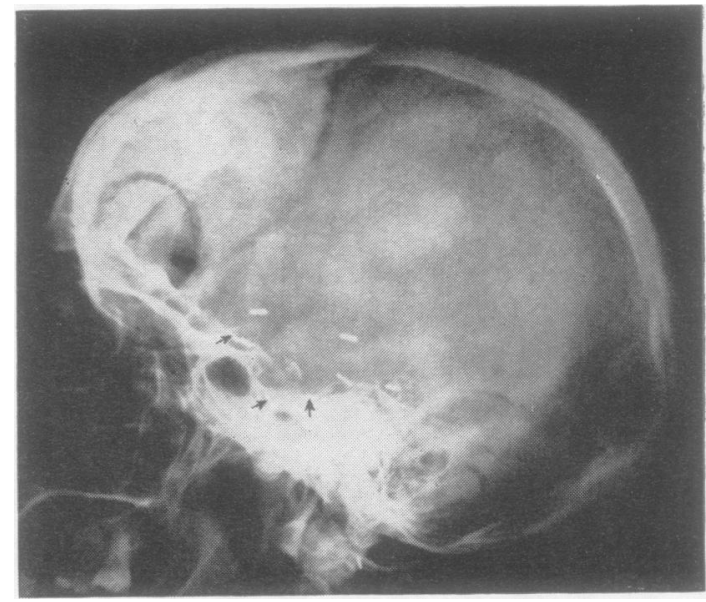

FIG. 4.-Post-operative skull radiograph with silver clip markers outlining the extent of the bilateral resections including the anterior hippocampal complex (approximately $6 \mathrm{~cm}$. posterior to the tip of the anterior temporal fossa).

after day without showing any practice effect and that he will read the same magazines over and over again without finding their contents familiar. This patient has even eaten luncheon in front of one of us (B. M.) without being able to name, a mere half-hour later, a single item of food he had eaten; in fact, he could not remember having eaten luncheon at all. Yet to a casual observer this man seems like a relatively normal individual, since his understanding

and reasoning are undiminished. two patients led us to study further all patients in the temporal-lobe series who were sufficiently cooperative to permit formal psychological testing. The operation sample included, in addition to the two radical resections, one bilateral removal of the uncus, extending $4 \mathrm{~cm}$. posterior to the temporal tips, and six bilateral medial temporal-lobe resections in which the removal was carried back 5 or $6 \mathrm{~cm}$. to include also a portion of the anterior hippocampus; in three of these six cases the temporal-lobe resection was combined with orbital undercutting. One unilateral case was also studied in which right inferior temporal lobectomy and hippocampectomy had been carried out for the relief of incisural herniation due to malignant oedema (Fig. 5). We found some memory impairment in all the bilateral cases in which the removal was carried far enough posteriorly to damage the hippocampus and hippocampal gyrus, but in only one of these six additional cases (D. C.) did the memory loss equal in severity that seen in the two most radical excisions. The case with bilateral excision of the uncus (in which the removal can have involved only the amygdaloid 


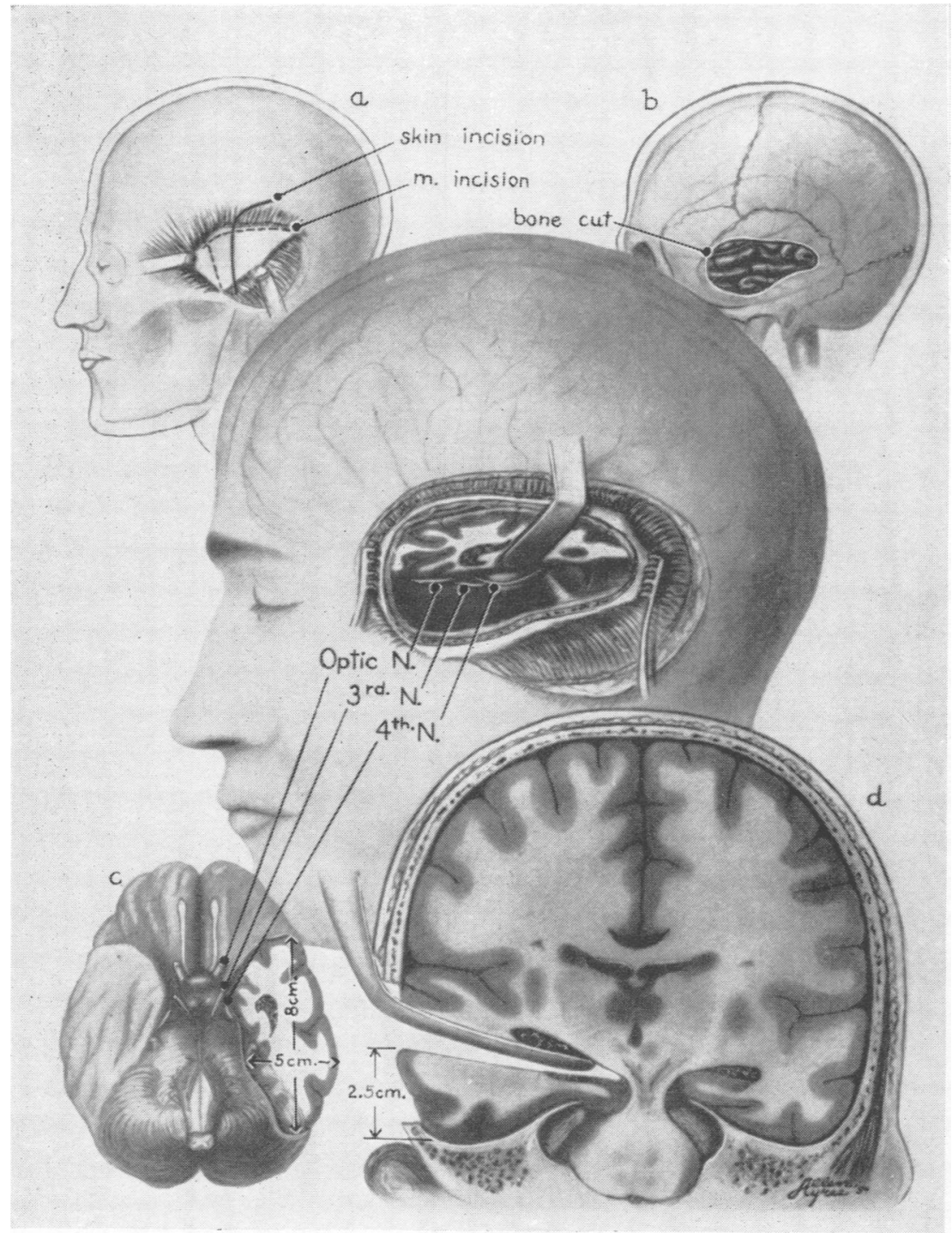

Fig. 5.-Unilateral inferior horizontal temporal lobectomy extending a distance of $8 \mathrm{~cm}$. posterior to the tip of the anterior temporal fossa. This operation is performed for incisural herniation of the temporal lobes (Case 10).

and peri-amygdaloid areas) showed excellent memory function. The unilateral operation, extensive as it was, has caused no lasting memory impairment, though some disturbance of recent memory was noted in the early post-operative period (Scoville, 1954); we now attribute this deficit to temporary interference with the functioning of the hippocampal zone of the opposite hemisphere by contralateral pressure.

The histories and individual test results for these 10 cases are reported below, and the Table summarizes the principal findings. For purposes of comparison the cases have been divided into three groups representing different degrees of memory impairment.

\section{Group I: Severe Memory Defect}

In this category are those patients who since operation appear to forget the incidents of their daily life as fast as they occur. It is interesting that all these patients were able to retain a three-figure number or a pair of unrelated words for several minutes, if care was taken not to distract them in the interval. However, they forgot the instant attention was diverted to a new topic. Since in normal life the focus of attention is constantly 
TABLE

CLASSIFICATION OF CASES

\begin{tabular}{|c|c|c|c|c|c|c|c|c|c|}
\hline \multirow[t]{2}{*}{ Cases } & \multirow{2}{*}{$\begin{array}{c}\text { Age at } \\
\text { Time of } \\
\text { Follow- } \\
\text { up } \\
\text { (yr.) }\end{array}$} & \multirow[t]{2}{*}{ Sex } & \multirow[t]{2}{*}{ Diagnosis } & \multirow[t]{2}{*}{ Operation } & \multirow{2}{*}{$\begin{array}{c}\text { Bi- } \\
\text { or } \\
\text { Uni- } \\
\text { lateral }\end{array}$} & \multirow{2}{*}{$\begin{array}{l}\text { Approximate } \\
\text { Extent of } \\
\text { Removal } \\
\text { along } \\
\text { Medial } \\
\text { Temporal } \\
\text { Lobes } \\
\text { (cm.) }\end{array}$} & \multirow{2}{*}{$\begin{array}{c}\text { Time } \\
\text { between } \\
\text { Operation } \\
\text { and } \\
\text { Testing } \\
\text { (mth.) }\end{array}$} & \multicolumn{2}{|c|}{ Wechsler Scale } \\
\hline & & & & & & & & $\begin{array}{c}\text { Intelli- } \\
\text { gence } \\
\text { Quotient }\end{array}$ & $\begin{array}{l}\text { Memory } \\
\text { Quotien }\end{array}$ \\
\hline $\begin{array}{l}\text { Group I: Severe } \\
\text { Memory Defect } \\
\text { Case 1, H. M. } \\
\text { Case 2, D. C. }\end{array}$ & $\begin{array}{l}29 \\
47\end{array}$ & $\begin{array}{l}\mathbf{M} \\
\mathbf{M}\end{array}$ & \multirow{2}{*}{$\begin{array}{l}\text { Epilepsy } \\
\text { Paranoid } \\
\text { schizophrenia } \\
\text { Manic-depressive } \\
\text { psychosis }\end{array}$} & \multirow{2}{*}{$\begin{array}{l}\text { Medial temporal } \\
\text { Medial temporal and } \\
\text { orbital undercutting } \\
\text { Medial temporal }\end{array}$} & $\begin{array}{l}\mathbf{B} \\
\mathbf{B}\end{array}$ & $\begin{array}{l}8 \\
5.5\end{array}$ & $\begin{array}{l}20 \\
21\end{array}$ & $\begin{array}{l}112 \\
122\end{array}$ & $\begin{array}{l}67 \\
70\end{array}$ \\
\hline Case 3, M. B. & 55 & $\mathbf{F}$ & & & B & 8 & 28 & 78 & 60 \\
\hline $\begin{array}{l}\text { Group II: Moderate } \\
\text { Memory Defect } \\
\text { Case 4, A. Z. }\end{array}$ & 35 & $\mathbf{F}$ & \multirow{4}{*}{$\begin{array}{l}\text { Paranoid } \\
\text { schizophrenia } \\
\text { Paranod } \\
\text { schizophrenia } \\
\text { Hebephrenic } \\
\text { schizophrenia } \\
\text { Schizophrenia } \\
\text { Schizophrenia }\end{array}$} & \multirow{4}{*}{$\begin{array}{l}\text { Medial temporal } \\
\text { Medial temporal and } \\
\text { orbital undercutting } \\
\text { Medial temporal and } \\
\text { orbital undercutting } \\
\text { Medial temporal } \\
\text { Medial temporal }\end{array}$} & B & 5 & 40 & 96 & 84 \\
\hline Case 5, M. R. & 40 & $\mathbf{F}$ & & & B & 5 & 39 & 123 & 81 \\
\hline Case 6, A. R. & 38 & $\mathbf{F}$ & & & B & 4.5 & 47 & \multirow{2}{*}{\multicolumn{2}{|c|}{$\begin{array}{l}\text { Incomplete } \\
\text { Incomplete } \\
\text { Incomplete }\end{array}$}} \\
\hline $\begin{array}{l}\text { Case 7, C. G. } \\
\text { Case 8, A. L. }\end{array}$ & $\begin{array}{l}44 \\
31\end{array}$ & $\begin{array}{l}\mathbf{F} \\
\mathbf{M}\end{array}$ & & & $\underset{\mathbf{B}}{\mathbf{B}}$ & $\begin{array}{l}5 \cdot 5 \\
6\end{array}$ & $\begin{array}{l}41 \\
38\end{array}$ & & \\
\hline $\begin{array}{l}\text { Group III: No } \\
\text { Memory Defect } \\
\text { Case 9, I. S. }\end{array}$ & 54 & $\mathbf{F}$ & Paranoid & Uncectomy & B & 4 & 53 & 122 & 125 \\
\hline Case 10, E. G. & 55 & $\mathbf{F}$ & $\begin{array}{l}\text { Incisural } \\
\text { herniation }\end{array}$ & $\begin{array}{l}\text { Inferior temporal } \\
\text { lobectomy }\end{array}$ & U-Rt. & 9 & 16 & 93 & 90 \\
\hline
\end{tabular}

changing, such individuals show an apparently complete anterograde amnesia. This severe defect was observed in the two patients having the most radical bilateral medial temporal-lobe excisions (with the posterior limit of removal approximately $8 \mathrm{~cm}$. from the temporal tips) and in one other case, a bilateral $5.5 \mathrm{~cm}$. medial temporal excision. These three cases will now be described.

Case 1, H. M. - This 29-year-old motor winder, a high school graduate, had had minor seizures since the age of 10 and major seizures since the age of 16 . The small attacks lasted about $\mathbf{4 0}$ seconds, during which he would be unresponsive, opening his mouth, closing his eyes, and crossing both arms and legs; but he believed that he could "half hear what was going on". The major seizures occurred without warning and with no lateralizing sign. They were generalized convulsions, with tongue-biting, urinary incontinence, and loss of consciousness followed by prolonged somnolence. Despite heavy and varied anticonvulsant medication the major attacks had increased in frequency and severity through the years until the patient was quite unable to work.

The aetiology of this patient's attacks is not clear. He was knocked down by a bicycle at the age of 9 and was unconscious for five minutes afterwards, sustaining a laceration of the left supra-orbital region. Later radiological studies, however, including two pneumoencephalograms, have been completely normal, and the physical examination has always been negative.

Electro-encephalographic studies have consistently failed to show any localized epileptogenic area. In the examination of August 17, 1953, Dr. T. W. Liberson described diffuse slow activity with a dominant frequenc禺 of 6 to 8 per second. A short clinical attack was said t\& be accompanied by generalized 2 to 3 per second spike and-wave discharge with a slight asymmetry in the centra leads (flattening on the left).

Despite the absence of any localizing sign, operation was considered justifiable for the reasons given above On September 1, 1953, bilateral medial temporal-lobe resection was carried out, extending posteriorly for a distance of $8 \mathrm{~cm}$. from the midpoints of the tips of the temporal lobes, with the temporal horns constituting the lateral edges of resection.

After operation the patient was drowsy for a few days, but his subsequent recovery was uneventful apart from the grave memory loss already described. There has been no neurological deficit. An electro-encephalogram taken one year after operation showed increased spikeand-wave activity which was maximal over the frontal areas and bilaterally synchronous. He continues to have seizures, but these are less incapacitating than before.

Psychological Examination.-This was performed on April 26, 1955. The memory defect was immediately apparent. The patient gave the date as March, 1953, and his age as 27. Just before coming into the examining room he had been talking to Dr. Karl Pribram, yet he had no recollection of this at all and denied that anyone had spoken to him. In conversation, he reverted constantly to boyhood events and seemed scarcely to realize that he had had an operation.

On formal testing the contrast between his good general intelligence and his defective memory was most striking. On the Wechsler-Bellevue Intelligence Scale he achieved a full-scale I.Q. rating of 112, which compares 
favourably with the pre-operative rating of 104 reported by Dr. Liselotte Fischer in August, 1953, the improvement in arithmetic being particularly striking. An extensive test battery failed to reveal any deficits in perception, abstract thinking, or reasoning ability, and his motivation remained excellent throughout.

On the Wechsler Memory Scale (Wechsler, 1945) his immediate recall of stories and drawings fell far below the average level and on the "associate learning" subtest of this scale he obtained zero scores for the hard word associations, low scores for the easy associations, and failed to improve with repeated practice. These findings are reflected in the low memory quotient of 67 . Moreover, on all tests we found that once he had turned to a new task the nature of the preceding one could no longer be recalled, nor the test recognized if repeated.

In summary, this patient appears to have a complete loss of memory for events subsequent to bilateral medial temporal-lobe resection 19 months before, together with a partial retrograde amnesia for the three years leading up to his operation; but early memories are seemingly normal and there is no impairment of personality or general intelligence.

Case 2, D. C. - This 47-year-old doctor was a paranoid schizophrenic with a four-year history of violent, combative behaviour. Before his illness he had been practising medicine in Chicago, but he had always shown paranoid trends and for this reason had had difficulty completing his medical training. His breakdown followed the loss of a lawsuit in 1950, at which time he made a homicidal attack on his wife which led to his admission to hospital. Since then both insulin and electro-shock therapy had been tried without benefit and the prognosis was considered extremely poor. On May 13, 1954, at the request of Dr. Frederick Gibbs and Dr. John Kendrick, a bilateral medial temporal-lobe resection combined with orbital undercutting was carried out at Manteno State Hospital (W. B. S., with the assistance of Dr. John Kendrick). The posterior limit of the removal was $5 \mathrm{~cm}$. from the sphenoid ridge, or roughly $5.5 \mathrm{~cm}$. from the tips of the temporal lobes, with the inferior horns of the ventricles forming the lateral edges of resection. Recording from depth electrodes at the time of operation showed spiking from the medial temporal regions bilaterally with some spread to the orbital surfaces of both frontal lobes, but after the removal had been completed a normal electro-encephalographic record was obtained from the borders of the excision.

Post-operative recovery was uneventful and there has been no neurological deficit. Since operation the patient has been outwardly friendly and tractable with no return of his former aggressive behaviour, although the paranoid thought content persists; he is considered markedly improved. But he too shows a profound memory disturbance. At Manteno State Hospital he was described as " confused", because since the operation he had been unable to find his way to bed and seemed no longer to recognize the hospital staff. However, no psychological examination was made there, and on November 29, 1955, he was transferred to Galesburg State Research Institute where he was interviewed by one of us (B. M.) on January 12, 1956.

Psychological Findings.-This patient presented exactly the same pattern of memory loss as H. M. He was courteous and cooperative throughout the examination, and the full-scale Wechsler I.Q. rating of 122 showed him to be still of superior intellect. Yet he had no idea where he was, explaining that naturally the surroundings were quite unfamiliar because he had only arrived there for the first time the night before. (In fact, he had been there six weeks.) He was unable to learn either the name of the hospital or the name of the examiner, despite being told them repeatedly. Each time he received the information as something new, and a moment later would deny having heard it. At the examiner's request he drew a dog and an elephant, yet half an hour later did not even recognize them as his own drawings. On the formal tests of the Wechsler Memory Scale his immediate recall of stories and drawings was poor, and the memory quotient of 70 is in sharp contrast to the high I.Q. level. As with H. M., once a new task was introduced there was total amnesia for the preceding one; in his own words, the change of topic confused him. This man did not know that he had had a brain operation and did not recall being at Manteno State Hospital, although he had spent six months there before the operation as well as six months post-operatively. Yet he could give minute details of his early life and medical training (accurately, as far as we could tell).

Case 3, M. B.-This 55-year-old manic depressive woman, a former clerical worker, was admitted to Connecticut State Hospital on December 27, 1951, at which time she was described as anxious, irritable, argumentative, and restless, but well-orientated in all spheres. Her recent memory was normal, in that she knew how long she had been living in Connecticut and could give the date of her hospital admission and the exact times of various clinic appointments. On December 18, 1952, a radical bilateral medial temporal-lobe resection was carried out, with the posterior limit of removal $8 \mathrm{~cm}$. from the temporal tips. Post-operatively she was stuporous and confused for one week, but then recovered rapidly and without neurological deficit. She has become neater and more even-tempered and is held to be greatly improved. However, psychological testing by Mr. I. Borganz in November, 1953, revealed a grave impairment of recent memory; she gave the year as 1950 and appeared to recall nothing of the events of the last three years. Yet her verbal intelligence proved to be normal.

She was examined briefly by B. M. in April, 1955, at which time she showed a global loss of recent memory similar to that of H. M. and D. C. She had been brought to the examining room from another building, but had already forgotten this; nor could she describe any other part of the hospital although she had been living there continuously for nearly three and a half years. On the Wechsler Memory Scale her immediate recall of stories and drawings was inaccurate and fragmentary, and delayed recall was impossible for her even with prompting; when the material was presented again she failed to recognize it. Her conversation centred around her early 
life and she was unable to give any information about the years of her hospital stay. Vocabulary, attention span, and comprehension were normal, thus confirming $\mathrm{Mr}$. Borganz' findings.

\section{Group II: Moderately Severe Memory Defect}

In this second category are those patients who can be shown to resi: some impression of new places and events, althisg they are unable to learn such arbitrary new associations as people's names and cannot be depended upon to carry out commissions. Subjectively, these patients complain of memory difficulty, and objectively, on formal tests, they do very poorly irrespective of the type of material to be memorized. The five remaining patients with bilateral medial temporal-lobe removals extending 5 or $6 \mathrm{~cm}$. posteriorly from the temporal tips make up this group. Only two of these patients were well enough to permit thorough testing, but in all five cases enough data were obtained to establish that the patient did have a memory defect and that it was not of the gross type seen in Group I. The individual cases are reported below.

Case 4, A. Z.-This 35-year-old woman, a paranoid schizophrenic, had been in Corn icut State Hospital for three years and extensiv $\ldots$ o-shock therapy had been tried without lasting be $\quad$ She was described as tense, assaultative, and se siy preoccupied. On November 29, 1951, bilate if medial temporal-lobe resection was carried out under local anaesthesia, the posterior limit of the removal being approximately $5 \mathrm{~cm}$. from the tips of the temporal lobes. During subpial resection of the right hippocan'mal cortex the surgeon inadvertently went through the arachnoid and injured by suction a portion of the right peduncle, geniculate, or hypothalamic region with immediate development of deep coma. The injury was visualized by extra-arachnoid inspection. Post-operatively the patient remained in stupor for 72 hours and exhibited a left spastic hemiplegia, contracted fixed pupils, strabismus, and lateral nystagmus of the right eye; vital signs remained constant and within normal limits. She slowly recovered the use of the left arm and leg and her lethargy gradually disappeared. By the seventh post-operative day she could walk without support and pupillary responses had returned to normal. The only residual neurological deficit has been a left homonymous hemianopia. Of particular interest was the dramatic post-operative improvement in her psychotic state with an early complete remission of her delusions, anxiety, and paranoid behaviour. At the same time she showed a retrograde amnesia for the entire period of her illness.

This patient was discharged from the hospital nine months after operation and is now able to earn her living as a domestic worker. However, she complains that her memory is poor, and psychological examination (April $27,1955)$ three and a half years post-operatively confirms this. But the deficit is less striking than in the three cases reported above. This patient, for example, was able to give the address of the house where she worked although she had been there only two days, and she could even describe the furnishings in some detail although she had not yet learned the name of her employer. She was also able to give an accurate, though sketchy, description of a doctor who had spoken to her briefly that morning and whom she had never seen before. However, she could recall very little of the conversation.

Formal testing at this time showed her intelligence to lie within the average range with no impairment of attention or concentration. The Wechsler-Bellevue I.Q. rating was 96 . On the Wechsler Memory Scale her immediate recall of stories was normal, but passing from one story to the next was enough to make her unable to recall the first one, though a few fragments could be recovered with judicious prompting. She showed the same rapid forgetting on the "visual retention" subtest, indicating that the memory impairment was not specific to verbal material. Finally, she was conspicuously unsuccessful on the " associate learning" subtest, failing to master a single unfamiliar word association. This examination as a whole provides clear evidence of an impairment of recent memory.

Case 5, M. R.-This 40-year-old woman, a paranoid schizophrenic with superimposed alcoholism, had been a patient at Norwich State Hospital for 11 years, receiving extensive electro-shock therapy. Bilateral medial tem poral-lobe resection combined with orbital undercutting? was carried out on January 17, 1952, the posterior exten of removal being roughly $5 \mathrm{~cm}$. from the temporal tips $\bar{\sigma}$ The patient has shown complete remission of psychotic symptoms and was discharged from the hospital on September 16, 1954, to the care of her family.

Psychological Examination.-This was performed of $\overrightarrow{0}$ April 29, 1955. Tests showed this woman to be of superior intelligence, with a full-scale I.Q. rating of 123 on the Wechsler Scale. However, she complained of poor memory, adding that she could remember faces and " the things that are important ", but that, to her great embarrassment, she forgot many ordinary daily happenings. Upon questioning she gave the year correctly but did not know the month or the day. She knew that she had had an operation in 1952 but did not recognize the surgeon (W. B. S.) nor recall his name. Formal testing revealed the same pattern of memory disturbance as A. Z. had shown, and the memory quotient of 81 compares most unfavourably with the high I.Q. rating. In conversation, she reverted constantly to discussion of her work during the years of depression and showed little knowledge of recent events.

Case 6, A. R.-This 38-year-old woman had been in hospital for five years with a diagnosis of hebephrenic schizophrenia. Before operation she was said to be noisy, combative, and suspicious, and electro-shock therapy had caused only transient improvement in this condition. On May 31, 1951, bilateral medial temporal-lobe resection combined with orbital undercutting was carried out, the posterior limit of removal being slightly less than $5 \mathrm{~cm}$. from the bisected tips of the temporal lobes. After operation the patient gradually became quieter and more 
cooperative and on September 29, 1952, she was discharged to her home. There have been no neurological sequelae.

Psychological Examination.-This was performed in April, 1955. Examination revealed a hyperactive woman, too excited and talkative for prolonged testing. She showed a restricted span of attention but scores on verbal intelligence tests were within the dull normal range. Moreover, she appeared to recall some recent happenings quite well. Thus, she knew that her daughter had caught a 7 o'clock train to New York City that morning to buy a dress for a wedding the following Saturday. She could also describe the clothes worn by the secretary who had shown her into the office. However, on formal testing some impairment of recent memory was seen, although unlike the other patients in this group she did succeed on some of the difficult items of the "associate learning " test. As with A. Z. and M. R., the deficit appeared most clearly on tests of delayed recall after a brief interval filled with some other activity. Thus, on the "logical memory " test she gave an adequate version of each story immediately after hearing it, but passing from one story to the next caused her to forget the first almost completely; similar results were obtained for the recall of drawings. We conclude that this patient has a memory impairment identical in type to that of the other patients in this group, but somewhat milder. It is interesting that she had a relatively small excision.

Case 7, C. G.-This 44-year-old schizophrenic woman had been in the hospital for 20 years without showing any improvement in her psychosis. On November 19, 1951, bilateral medial temporal-lobe resection was carried out under local anaesthesia, the posterior limit of removal being $5.5 \mathrm{~cm}$. from the tips of the temporal lobes. There was temporary loss of consciousness during the resection but the patient was fully conscious at the end of the procedure and post-operative recovery was uneventful. There has been no neurological deficit. She is considered to be in better contact than before but more forgetful.

This patient was examined at Norwich State Hospital in April, 1955, and although she was too distractible for prolonged testing, it was possible to show that she remembered some recent events. For example, she knew that she had been working in the hospital beauty parlour for the past week and that she had been washing towels that morning. Yet formal memory testing revealed the same deficit as that shown by A. Z. and M. R., though less extensive data were obtained in this case.

Case 8, A. L.-This 31-year-old schizophrenic man had been a patient at Norwich State Hospital since October, 1950. He had first become ill in August, 1950, demonstrating a catatonic type of schizophrenia with auditory and visual hallucinations. On January 31, 1952, bilateral medial temporal-lobe resection combined with orbital undercutting was carried out, the removal extending posteriorly for a distance of $6 \mathrm{~cm}$. along the mesial surface of the temporal lobes. Recovery was uneventful and no neurological deficit ensued. The patient has been more tractable since the operation but he is still subject to delusions and hallucinations. $\mathrm{He}$ is said to have a memory defect. When interviewed by B. M. in April, 1955, he was found to be too out of contact for extensive formal testing. However, he was able to recall the examiner's name and place of origin 10 minutes after hearing them for the first time, and this despite the fact that the interval had been occupied with other tasks. He could also recognize objects which had been shown to him earlier in the interview, selecting im correctly from others which he had not seen befc. "But his immediate recall of drawings and stories was faulty and these were forgotten completely once his attention was directed to a new topic.

In this patient we stress the negative findings: despite his evident psychosis he did not show the severe memory loss typical of the patients in Group 1. Yet the brief psychological examination and the hosptal record both indicate some impairment of recent memory, though no reliable quantitative studies could be made.

\section{Group III: No Persistent Memory Defect}

Case 9, I. S.-This 54-year-old woman had a 20-year history of paranoid schizophrenia, with auditory hallucinations and marked emotional lability. She had attempted suicide on several occasions. On November 16, 1950, six months after admission to a state hospital, a bilateral medial temporal lobectomy was carried out under local anaest ${ }^{2}$ ia with sectioning of the tips of the temporal lobes and . $\quad \cdot$ ' suction removal of the medial portion, extending $1 \quad \mathrm{~cm}$. to include the uncus and amygdala. Thus this a conservative bilateral removal, sparing the hip tampal region. The operation was complicated by acci.tental damage to the midbrain from the electrocautery, causing the patient to give a convulsive twitch wi.ch was followed by coma and extensive rigidity. After operation she was somnolent for a time with continuing rigidity, more marked on the left side than on the right. Vital signs were normal. She required traction to prevent flexure spasm contractures. There was slow improvement over the ensuing two months, with some residual clumsiness and spasticity of gait. For a time the patient's mental state was worse than before operation, but within three months she had improved markedly, with increased gentleness, diminished auditory hallucinations, and no depression. She ultimately showed the best result of all the cases in this series and was discharged from the hospital five months after operation.

This patient was re-examined on May 11, 1956. She shows a complete remission of her former psychotic behaviour and is living at home with her husband and leading a normal social life. Her hallucinations have ceased. Upon neurological examination she shows some $25 \%$ residual deficit, manifested chiefly by spastic incoordination of gait and similar but less marked incoordination of the arms. The deep leg reflexes are increased to near clonus, but there is no Babinski sign. Arm reflexes are moderately increased and abdominal reflexes absent. Smell is completely lost but all other sense modalities are intact and other cranial nerves normal.

Psychological Findings.-The patient was examined psychologically in April, 1955. From the standpoint of 
memory, this patient presents a complete contrast to the cases reported above, obtaining excellent scores for both immediate and delayed recall of stories, drawings, and word associations, and describing accurately episodes from the relatively early post-operative period. The memory quotient of 125 is consistent with the I.Q. level of 122 , and both would be classed as superior. This is so despite prolonged psychosis, intensive electro-shock therapy, and brain-stem damage of undetermined extent.

Case 10, E. G.-This 55-year-old woman developed malignant oedema after removal of a huge, saddle-type meningioma from the right sphenoid ridge; the pupils were dilated, she lost consciousness, and vital signs began to fail. A diagnosis of incisural hippocampal herniation was made, and, as a life-saving measure, unilateral nondominant inferior temporal lobectomy was carried out, with deliberate resection of the hippocampus and hippocampal gyrus to a distance of $9 \mathrm{~cm}$. from the tip of the temporal lobe. (The operative procedure is illustrated in Fig. 5.) Vital signs improved immediately and consciousness gradually returned, but for a few weeks the patient showed a disturbance of recent memory resembling that seen in our bilateral cases. However, follow-up studies in April, 1955, 16 months after operation, showed no residual memory loss. Both immediate and delayed recall were normal and the memory quotient of 90 was completely consistent with the I.Q. level of 93. Neurological examination at this time showed a left homonymous visual field defect with macular sparing but no other deficit.

\section{Discussion}

The findings in these 10 cases point to the importance of the hippocampal region for normal memory function. All patients in this series having bilateral medial temporal-lobe resections extensive enough to damage portions of the hippocampus and hippocampal gyrus bilaterally have shown a clear and persistent disturbance of recent memory, and in the two most radical excisions (in . which the posterior limit of removal was at least $8 \mathrm{~cm}$. from the temporal tips) the deficit has been particularly severe, with no improvement in the two or more years which have elapsed since operation. These observations suggest a positive relationship between the extent of destruction to the hippocampal complex specifically and the degree of memory impairment. The correlation is not perfect, since D. C., who had only a $5.5 \mathrm{~cm}$. removal, showed as much deficit as did the two cases of most radical excision. Moreover, in the absence of necropsy material we cannot be sure of the exact area removed.

In all these hippocampal resections the uncus and amygdala have also of course been destroyed. Nevertheless the importance of the amygdaloid and periamygdaloid region for memory mechanisms is open to question, considering the total lack of memory impairment in the bilateral uncectomy case (I. S.), in which a $4 \mathrm{~cm}$. medial-temporal lobe removal was made. But not enough is known of the effects of lesions restricted to the hippocampal area itself to permit assessment of the relative contributions of these two regions. This is a question on which selective ablation studies in animals could well shed important light, but unfortunately the crucial experiments have yet to be done (Jasper, Gloor, and Milner, 1956).

The role of the hippocampus specifically has been discussed in some clinical studies. Glees and Griffith (1952) put forward the view that bilateral destruction of the hippocampus in man causes recentmemory loss and mental confusion, citing in support of this a somewhat unconvincing case of Grünthal (1947) and also a case of their own in which the hippocampus, the hippocampal and fusiform gyri, and $75 \%$ of the fornix fibres had been destroyed bilaterally by vascular lesion, but in which the rest of the brain appeared normal at necropsy. Interestingly enough, the amygdaloid nuclei were found to be intact as were the mamillary bodies. This patient showed marked anterograde and retrograde amnesia.

More recently Milner and Penfield (1955) have described a memory loss similar in all respects to $\bigcirc$ that shown by our patients, in two cases of unilateral $\stackrel{\circ}{\circ}$ partial temporal lobectomy in the dominant hemisphere. In one case the removal was carried out ino two stages separated by a five-year interval, and theog memory loss followed the second operation only, at which time the uncus, hippocampus, and hippocampal gyrus alone were excised. Although these authors had carried out careful psychological testing in over 90 other cases of similar unilateral operation, only in these two cases was a general memory loss found. To account for the unusual deficit, they have assumed that there was in each case a pre-operatively unsuspected, but more or less completely destructive lesion of the hippocampal area of the opposite hemisphere. The unilateral operation would then deprive the patient of hippocampal function bilaterally, thus causing memory loss. The present study provides strong support for this interpretation.

Memory loss after partial bilateral temporal lobectomy has been reported by Petit-Dutaillis, Christophe, Pertuiset, Dreyfus-Brisac, and Blanc (1954) but in their patient the deficit was a transient one, a finding which led these authors to question the primary importance of the temporal lobes for memory function. However, their temporal lobe removals were complementary to ours in that they destroyed the lateral neocortex bilaterally but spared the hippocampal gyrus on the right and the uncus and hippocampus on the left. It therefore seems likely that the memory loss was due to temporary 
interference with the functioning of the hippocampal system, which later recovered.

We have stated that the loss seen in patients with bilateral hippocampal lesions is curiously specific to the domain of recent memory; neither in our cases nor in those of Milner and Penfield was there any deterioration in intellect or personality as a result of hippocampal resection. It appears important to emphasize this, since Terzian and Dalle Ore (1955) have described gross behavioural changes (affecting memory, perception, and sexual behaviour) after bilateral temporal lobectomy in man; they consider these changes comparable to Klüver and Bucy's (1939) findings after radical bilateral temporal lobectomy in the monkey. But Terzian and Ore included not only the uncal and hippocampal areas, but also the lateral temporal cortex in their bilateral removal. In contrast to the grossly deteriorated picture they describe, we find that bilateral resections limited to the mesial temporal region cause no perceptual disturbance, even on visual tests known to be sensitive to unilateral lesions of the temporal neocortex (Milner, 1954).

The findings reported herein have led us to attribute a special importance to the anterior hippocampus and hippocampal gyrus in the retention of new experience. But the hippocampus has a strong and orderly projection to the mamillary bodies (Simpson, 1952), and as early as 1928 Gamper claimed that lesions of the mamillary bodies were commonly found in amnesic states of the Korsakoff type. Moreover, Williams and Pennybacker (1954) have carried out careful psychological studies of 180 patients with verified intracranial lesions and find that a specific deficit in recent memory is most likely to occur when the lesion involves the mamillary region. It is possible, then, that when we have two interrelated structures (hippocampus and mamillary bodies) damage to either can cause memory loss, a point which has been emphasized by Jasper and others (1956). In view of these findings it is interesting that sectioning the fornix bilaterally, and thereby interrupting the descending fibres from the hippocampus, appears to have little effect on behaviour (Dott, 1938; Garcia Bengochea, De la Torre, Esquivel, Vieta, and Fernandez, 1954), though a transient memory deficit is sometimes seen (Garcia Bengochea, 1955).

To conclude, the observations reported herein demonstrate the deleterious effect of bilateral surgical lesions of the hippocampus and hippocampal gyrus on recent memory. The relationship between this region and the overlying neocortex in the temporal lobe needs further elucidation, as does its relationship to deeper-lying structures.

\section{Summary}

Bilateral medial temporal-lobe resection in man results in a persistent impairment of recent memory whenever the removal is carried far enough posteriorly to damage portions of the anterior hippocampus and hippocampal gyrus. This conclusion is based on formal psychological testing of nine cases (eight psychotic and one epileptic) carried out from one and one-half to four years after operation.

The degree of memory loss appears to depend on the extent of hippocampal removal. In two cases in which bilateral resection was carried to a distance of $8 \mathrm{~cm}$. posterior to the temporal tips the loss was particularly severe.

Removal of only the uncus and amygdala bilaterally does not appear to cause memory impairment.

A case of unilateral inferior temporal lobectomy with radical posterior extension to include the major portion of the hippocampus and hippocampal gyrus showed no lasting memory loss. This is consistent with Milner and Penfield's negative findings in a long series of unilateral removals for temporal-lobe epilepsy.

The memory loss in these cases of medial temporal-lobe excision involved both anterograde and some retrograde amnesia, but left early memories and technical skills intact. There was no deterioration in personality or general intelligence, and no complex perceptual disturbance such as is seen after a more complete bilateral temporal lobectomy.

It is concluded that the anterior hippocampus and hippocampal gyrus, either separately or together, are critically concerned in the retention of current experience. It is not known whether the amygdala plays any part in this mechanism, since the hippocampal complex has not been removed alone, but always together with uncus and amygdala.

\section{REFERENCES}

Dott, N. M. (1938). In Clark, W. E., Le Gros, Beattie, J., Riddoch, G., and Dott, N. M. The Hypothalamus: Morphological, Functional, Clinical and Surgical Aspects. Oliver and Boyd, Edinburgh.

Gamper. E. (1928). Dtsch. Z. Nervenheilk., 102, 122.

Garcia Bengochea, F. (1955). Personal Communication.

De La Torre, O., Esquivel, O., Vieta, R., and Fernandez, C. (1954). Trans. Amer. neurol. Ass., 79, 176.

Glees, P., and Griffith, H. B. (1952). Mschr. Psychiat. Neurol., 123, 193. Grünthal, E. (1947). Ibid., 113, 1 .

Jasper, H., Gloor, P., and Milner, B. (1956). Ann. Rev. Physiol., 18, 359. Klüver, H., and Bucy, P. C. (1939). Arch. Neurol. Psychiat. (Ćhicago), 42, 979.

MacLean, P. D. (1952). Electroenceph. clin. Neurophysiol., 4, 407. Milner, B. (1954). Psychol. Bull., 51, 42.

-, and Penfield, W. (1955). Trans. Amer. neurol. Ass., 80, 42.

Petit-Dutaillis, D., Christophe, J., Pertuiset, B., Dreyfus-Brisac, C., and Blanc, C. (1954). Rev. neurol. (Paris), 91, 129.

Pribram, K. H., and Kruger, L. (1954). Ann. N.Y. Acad. Sci., 58, 109. Scoville, W. B. (1954). J. Neurosurg., 11, 64.

- Dunsmore, R. H., Liberson, W.'T., Henry, C. E., and Pepe, A (1953). Res. Publ. Ass. nerv. ment. Dis., 31, 347.
(19., Wilk, E. K., and Pepe, A. J. (1951). Amer. J. Psychiat., 107,730 .

Simpson, D. A. (1952). Journal of Neurology, Neurosurgery and

Psychiatry, 15, 79.
Terzian, H., and Dalle Ore, G. (1955). Neurology, 5, 373.

Wechsler, D. (1945). J. Psychol., 19, 87.

Williams, M., and Pennybacker, J. (1954). Journal of Neurology, Neurosurgery and Psychiatry, 17, 115. 